\title{
Health Care Quality Perceptions among Foreign-Born Latinos and the Importance of Speaking the Same Language
}

\author{
Hector M. González, PhD, William A. Vega, PhD, and Wassim Tarraf, MA
}

Objectives: To examine the relationship between patients' English proficiency, patient-provider language concordance, and health care quality among foreign-born Latinos in the United States.

Methods: National probability sample data (from the Pew Hispanic Center/Robert Wood Johnson Foundation Latino Health Survey) were analyzed from telephone interviews with foreign-born Latino adults $(n=2921$; aged 18 years and older $)$. There were 3 main outcomes related to clinical experiences using self-reports of confusion, frustration, and perception of poor quality of care received because of English-speaking ability and accent bias, as well as an overall rating of care quality. Patients' English proficiency and patient-provider language concordance were the chief predictors.

Results: Patients' English proficiency was not significantly associated with the 3 clinical experiences measures and marginally so with overall care quality ratings. Language concordance was significantly associated with a lower likelihood of confusion, frustration, and language-related poor quality ratings, and was positively associated with patient-reported overall quality of care. In addition, providers' language concordance attenuated the statistical significance of the effects of patients' English proficiency when both were modeled simultaneously.

Conclusion: Patient-provider language concordance plays an important role in communication barriers among foreign-born Latino patients. Our findings indicate that although patients' language proficiency is important to health care quality ratings, what may matter more is when patient and provider speak the same language. (J Am Board Fam Med 2010;23:745-752.)

Keywords: Quality of Health Care, Latinos, Hispanics, Language, Cross-Cultural Issues

One in 5 Americans speaks a language other than English at home, approximately one half of whom reported speaking "a little" English or "not at all."1 Latinos, who now comprise more than $15 \%$ of the United States population, are the largest and fastest

This article was externally peer reviewed.

Submitted 25 November 2009; revised 11 August 2010; accepted 11 August 2010.

From the Department of Family Medicine and Public Health Sciences and the Institute of Gerontology, Wayne State University, Detroit, MI (HMG, WT); the Program for Research on Black Americans, Institute of Social Research, University of Michigan, Ann Arbor (HMG); and the Edward R. Roybal Institute on Aging, University of Southern California, Los Angeles (WAV).

Funding: Funding was provided by the National Institute of Mental Health grants MH 67726 and MH 84994 (HMG). Support was also provided by the Robert Wood Johnson Foundation, Network for Multicultural Research on Health and Healthcare (HMG, WAV).

Conflict of interest: none declared.

Corresponding author: Hector M. González, $\mathrm{PhD}$, Institute of Gerontology, Wayne State University, 87 East Ferry Street, 234 Knapp Building, Detroit, MI 48202 (E-mail: hmgonzalez@med.wayne.edu). growing ethnic/racial group. The US Census projects that by the year 2050 approximately one third of the US population will be Latino. As this population continues to grow at rates that exceed most previous estimates, demand for goods and services that meet the needs of Latinos will continue to influence market trends in the United States, including health care. ${ }^{2}$ With half of Latinos not speaking English "very well," quality health care will be achieved through meeting the language needs of Latino "consumers." Indeed, the Institute of Medicine and the Agency for Health Care Research and Quality have identified removing language barriers as essential to reducing ethnic/racial health care disparities. ${ }^{3,4}$ As such, understanding the relationship between language and health care quality has important public health implications for providing services in an increasingly diverse US population.

Highly sensitive diagnostic tests continue to improve medical practice science; however, clinical interviews by skillful health care providers will always 
be the foundation of quality health care. When the patient and provider speak different languages, clinical interviews are compromised and the quality of health care is negatively affected. ${ }^{5}$ Research has demonstrated that Latino patients with limited proficiency in English report poorer health and lower health care quality. ${ }^{6,7}$ The use of professional interpreters improves communication by reducing errors and comprehension that indirectly improve use, clinical outcomes, and satisfaction with care; however, in practice, interpreters are often ad hoc family members or office staff with highly variable levels of translation training and skills. ${ }^{8}$ Although health care providers who have historically served Latinos may be better equipped with Spanish-speaking providers and professional interpreters, many health care catchments in other parts of the United States are being caught off guard by the rapidly changing demographics of their markets. ${ }^{\text {? }}$

Previous research points to different factors that contribute to language barriers in health care. Several studies have implicated patients' acculturation or limited proficiency in English as the problem, ${ }^{6,7,10}$ whereas others have suggested that problems arise when the patient's and provider's languages are not concordant. ${ }^{11,12}$ The purpose of this study was to evaluate the relationship and relative contribution of English proficiency and language concordance to health care quality ratings. To achieve this objective we used a nationally representative survey of Latino adults' health care. We anticipated that language concordance would be the primary determinant of quality ratings among "consumers" of Latino health care.

\section{Methods}

Study participants were part of a stratified, random telephone survey of adult Latinos (ages 18 years and older) that had been designed to produce a statistically representative sample of Latinos in the contiguous United States. Respondents were identified as Latino if they answered yes to the question, Are you, yourself, of Hispanic or Latino origin or descent such as Mexican, Puerto Rican, Cuban, Dominican, Central or South American, Caribbean, or some other Latin American background? The survey interviews were conducted in either English or Spanish depending on the respondent's preference. The final telephone interview sample for analysis consisted of 3899 persons after exclu- sion of 114 participants who were not included in the analysis because they refused to give their age or other key demographic variables and who had, in general, more refusals during the interview than other participants. Adjustment after stratification consisted of sampling weights modification to reflect the Latino population distribution by age, sex, nativity, and education according to the March 2007 Current Population Survey. ${ }^{2}$ Because our aim was to evaluate the relationship between language and health care quality, which is less of an issue among US-born Latinos, the study focused on the foreign-born subpopulation $(\mathrm{n}=2921)$.

Telephone interviews were conducted as part of the Pew Hispanic Center/Robert Wood Johnson Foundation Hispanic/Latino Health survey in the Summer of 2007 and had a response rate of $39.5 \% .{ }^{13}$ This response rate was comparable to other telephone surveys (eg, Behavioral Risk Factor Surveillance System; 41.2\% response rate in 2004 and the California Health Interview Survey; 38.5\% in 2004). Probability weights after the survey were used to adjust for disproportionalities, including nonresponse bias according to the American Association for Public Opinion Research guidelines. ${ }^{14}$

\section{Main Outcomes}

We examined 3 outcomes related to clinical experiences and an overall rating of the quality of health care received. The first 2 outcomes assessed whether respondents were "confused by the information they were given" and "frustrated by a lack of information or an inability to find what they wanted to know" during their most recent clinical encounter (ie, visit to a health care provider). The third outcome assessed perceptions of language bias by using respondents' self-reports of receiving poor quality of medical treatment because of their "accent or how you speak English." All 3 of these outcomes were coded dichotomously $(0=$ no; $1=$ yes $)$. The fourth outcome was a 4-point, Likert-type rating scale (excellent, good, fair, or poor) of overall quality of care that had been received during the past 12 months. Medical care was broadly defined and included community clinics or health centers, doctor's offices, hospital emergency rooms and outpatient departments, or some other places specified by respondents. The care quality outcome was coded on a scale of 1 through 4, with higher values representing better rating of care quality. 


\section{Main Predictors}

To address the study aims, we constructed 2 language measures. All indicators used to create these measures were based on respondents' self-reports. The first language measure was an English proficiency construct created by adding 2 Likert-type scale items quantifying verbal and written English proficiency. Both proficiency items were coded so that higher values reflected higher English language proficiency $(1=$ not at all; $2=$ just a little; $3=$ pretty well; $4=$ very well). The resulting indicator values ranged from 0 (indicating a minimum level of English proficiency) to 6 (maximum level of English proficiency). The second measure was language concordance, which was operationalized dichotomously $(0=$ discordant; $1=$ concordant) by using 2 items. First, an indicator defined as linguistic facility was created by comparing respondents' verbal English and Spanish language proficiency scores. Both English and Spanish verbal proficiencies were assessed using Likert-type scales $(1=$ not at all; $2=$ just a little; $3=$ pretty well; and $4=$ very well). The resulting indicator consisted of 3 categories: (1) respondents whose verbal English language proficiency score exceeded their verbal Spanish proficiency were classified as "better English"; (2) respondents whose Spanish verbal language proficiency score exceeded their English score were classified as "better Spanish"; and (3) respondents with equal English and Spanish verbal language proficiency scores were classified as "bilingual." Second, the language that care providers used during clinical encounters was measured using a dichotomous indicator based on respondents' self-reported answers to the question, "When you see a doctor or other health care provider, in what language is the appointment usually conducted?" (0 = Spanish; 1 = English). Respondents designated as "better Spanish" and whose language of clinical encounter was conducted in English were classified as "discordant"; all other respondents were assigned as "concordant."

Three covariates were included in the model to account for the possibility that language effects could be attenuated by socioeconomic factors that enable access to health care. Education was divided into 5 categories based on years of schooling completed (ie, 0-8 years; 9-11 years; high school or equivalent; some college or vocational training; and a college degree or higher). Annual household income was also broken into 5 groups $(\$ 0-\$ 14,999 ; \$ 15,000-\$ 24,999$;
$\$ 25,000-\$ 34,999 ; \$ 35,000-\$ 59,999$; and $\geq \$ 60,000$ ). Finally, the presence or absence of health insurance coverage (ie, employee-based, private, or government program) was a dichotomous measure $(0=$ uninsured; $1=$ insured). All models were adjusted for age (continuous) and sex $(0=$ male; $1=$ female $)$.

\section{Analytic Approach}

Stata software (version 10.1, StataCorp, LP, College Station, TX) procedures designed to analyze complex survey designs were used in all our analyses to account for the clustered design of our sample. Estimates were weighted to ensure proper representation of the US Latino population. The sampling weights accounted for unequal probabilities of selection, nonresponse, and after stratification.

First, sample estimates describing demographic characteristics were calculated. Next, a series of logistic regressions were used to model hypothesized relationships between our 3 clinical experience outcomes and our predictors and covariates. Then a series of ordered logit models were run to estimate the effects of those predictors and covariates on our fourth outcome: the ordered categorical indicator of care quality. To do so, generalized ordered logit functionality (gologit2) procedures were used to test for possible violations of the parallel odds assumptions. ${ }^{15}$ The gologit2 functionality fits partial proportional odds models, thus allowing us to examine whether parallel lines assumptions are unwarranted because of differential effects of our predictors on the categories of our outcome variable. Both variable specific and global Wald tests indicated that the parallel lines assumptions at the 0.01 level would not be violated. As a result, ordered logit models, which produce more parsimonious and easier to interpret results relative to the generalized ordered logit functionality, using StataCorp's ologit program were deemed acceptable. Three ordered logistic regression models were fit. Models 1 and 2 tested the effects of English language proficiency and language concordance on overall assessment of quality of care separately. Model 3 accounted for both predictors simultaneously to test whether and how the effects of these predictors are statistically attenuated. 


\section{Results}

\section{Univariate Statistics}

Sample characteristics are provided in Table 1. The study respondents had an average age of 40.6 years. Approximately two-fifths (40.9\%) reported having a high school degree or more, and only $7.5 \%$ indicated an income of $\geq \$ 60,000$. Less than two-thirds $(59.6 \%)$ reported having some form of health insurance. Finally, 17.6\% were classified as having had a language-discordant clinical encounter.

\section{Language and Clinical Experience Logit Model Results}

English proficiency was not statistically associated with any of the clinical experience outcomes examined (Table 2; English proficiency models). Highincome classification $(\geq \$ 60,000)$ and being insured were associated with a lower likelihood of reporting confusion and frustration.

Language concordance (Table 2; Language concordance models) was significantly associated with lower odds of experiencing confusion, frustration, and reporting poor care quality because of perceived language discrimination. As with the previous models, high-income classification $(\geq \$ 60,000)$ and being insured were associated with a lower

Table 1. Sample Characteristics of the Foreign-born Latino Respondents in the Pew Hispanic Center/Robert Wood Johnson Foundation Latino Health Survey ( $\mathrm{n}=2921)$

\begin{tabular}{lc}
\hline & Foreign Born \\
\hline English proficiency (mean [SE]) & $2.56(0.04)$ \\
Age (mean years [SE]) & $40.59(0.3)$ \\
Language concordant & $82.4(0.9)$ \\
Female & $46.6(1.1)$ \\
Health insurance coverage & $59.6(1)$ \\
Income (US\$) & \\
$0-14,999$ & $27.8(0.9)$ \\
$15,000-24,999$ & $26.2(0.9)$ \\
$25,000-34,999$ & $20.5(0.9)$ \\
$35,000-59,999$ & $18(0.9)$ \\
$\geq 60,000$ & $7.5(0.6)$ \\
Education & \\
$0-8$ years & $30(0.9)$ \\
$9-11$ years & $19.7(0.8)$ \\
High school graduate & $27.1(1)$ \\
Some college & $13.8(0.8)$ \\
College degree or higher & $9.4(0.6)$ \\
\hline
\end{tabular}

Values provided as percent (SE) unless otherwise indicated. likelihood of reporting confusion or frustration. Finally, respondents who reported 9 to 11 years of education and those who reported having a college degree had a lower likelihood of reporting frustration and poor quality of care because of language bias relative to those who reported $\leq 8$ years of education.

\section{Language and Health Care Quality Ordered Logit Model Results}

Table 3 shows the ordered logistic regression results. In model 1, English proficiency was marginally associated with an increase in the proportional odds of a higher assessment of quality of care. High income $(\geq \$ 60,000)$, higher education, and being insured were all significantly associated with higher odds of reporting better care quality. In model 2, language concordance was significantly associated with increased odds of a higher assessment of care quality. As with model 1 , high income $(\geq \$ 60,000)$, higher education, and being insured were all significantly associated with higher odds of reporting better quality of care. Finally, in model 3, both English proficiency and language concordance were included. Under this formulation, the effects of English proficiency were completely attenuated by language concordance. Clinical language concordance remained significantly associated with increased odds of higher quality of care assessment. The direction and significance of all other effects remained largely unchanged.

\section{Discussion}

We found that patient-provider language concordance was associated with foreign-born Latino patients reporting less confusion and frustration with information received from providers during recent clinical encounters and better overall ratings of health care quality. In addition, when patient-provider language was discordant, Latinos rated their health care lower and reported that their accent and English-speaking ability was related to their receipt of poor quality health care. English proficiency alone was not strongly associated with health care quality ratings. Furthermore, patient-provider language concordance largely explained any relationship between English language proficiency and health care quality ratings. The relationship we found between language concordance and health care quality ratings was not explained by other 
Table 2. Logistic Regression Results from the Pew Hispanic Center/Robert Wood Johnson Foundation Latino Health Survey of Patient and Provider Language Use and Health Care Quality Ratings among Foreign-born Latinos Who Received Medical Care during the Past 12 Months in the United States $(n=2663) *$

\begin{tabular}{|c|c|c|c|}
\hline & Confusion Experience & Frustration Experience & Healthcare Language Bias \\
\hline & & English Proficiency & \\
\hline English proficiency & $0.98(0.92-1.05)$ & $0.98(0.92-1.04)$ & $0.92(0.82-1.03)$ \\
\hline \multicolumn{4}{|l|}{ Income (US\$) } \\
\hline $0-14,999$ & 1.00 & 1.00 & 1.00 \\
\hline $15,000-24,999$ & $0.86(0.65-1.13)$ & $0.99(0.76-1.29)$ & $0.95(0.60-1.51)$ \\
\hline $25,000-34,999$ & $0.87(0.65-1.18)$ & $0.92(0.69-1.24)$ & $0.93(0.55-1.56)$ \\
\hline $35,000-59,999$ & $1.00(0.72-1.39)$ & $1.21(0.88-1.66)$ & $1.23(0.67-2.27)$ \\
\hline$\geq 60,000$ & $0.44^{*}(0.25-0.77)$ & $0.53^{\dagger}(0.32-0.88)$ & $0.72(0.28-1.88)$ \\
\hline \multicolumn{4}{|l|}{ Education } \\
\hline $0-8$ years & 1.00 & 1.00 & 1.00 \\
\hline $9-11$ years & $0.92(0.68-1.24)$ & $0.78^{\ddagger}(0.58-1.03)$ & $0.62(0.36-1.09)$ \\
\hline High school graduate & $1.01(0.76-1.33)$ & $0.92(0.70-1.21)$ & $0.94(0.59-1.52)$ \\
\hline Some college & $0.77(0.51-1.15)$ & $0.84(0.57-1.23)$ & $0.87(0.42-1.81)$ \\
\hline College degree or higher & $0.81(0.52-1.28)$ & $0.71(0.45-1.11)$ & $0.56(0.26-1.20)$ \\
\hline \multirow[t]{2}{*}{ Health insurance coverage } & $0.68 *(0.55-0.85)$ & $0.75^{*}(0.60-0.92)$ & $0.90(0.60-1.36)$ \\
\hline & & $\underline{\text { Language Concordance }}$ & \\
\hline Language concordance & $0.78^{\ddagger}(0.59-1.01)$ & $0.72 *(0.55-0.94)$ & $0.40 *(0.27-0.61)$ \\
\hline \multicolumn{4}{|l|}{ Income (US\$) } \\
\hline $0-14,999$ & 1.00 & 1.00 & 1.00 \\
\hline $15,000-24,999$ & $0.86(0.65-1.14)$ & $1.00(0.77-1.30)$ & $0.93(0.58-1.48)$ \\
\hline $25,000-34,999$ & $0.86(0.64-1.17)$ & $0.91(0.68-1.23)$ & $0.88(0.52-1.48)$ \\
\hline $35,000-59,999$ & $1.03(0.74-1.42)$ & $1.22(0.89-1.68)$ & $1.13(0.62-2.04)$ \\
\hline$\geq 60,000$ & $0.44^{*}(0.25-0.77)$ & $0.52 *(0.31-0.85)$ & $0.60(0.24-1.50)$ \\
\hline \multicolumn{4}{|l|}{ Education } \\
\hline $0-8$ years & 1.00 & 1.00 & 1.00 \\
\hline $9-11$ years & $0.87(0.65-1.17)$ & $0.74^{\dagger}(0.55-0.98)$ & $0.54^{\dagger}(0.31-0.94)$ \\
\hline High school graduate & $0.93(0.71-1.22)$ & $0.85(0.65-1.11)$ & $0.79(0.49-1.27)$ \\
\hline Some college & $0.70^{\ddagger}(0.48-1.03)$ & $0.78(0.55-1.11)$ & $0.69(0.35-1.34)$ \\
\hline College degree or higher & $0.76(0.50-1.15)$ & $0.64^{\dagger}(0.42-0.97)$ & $0.47^{\dagger}(0.23-0.96)$ \\
\hline Health insurance coverage & $0.69^{*}(0.55-0.87)$ & $0.73 *(0.59-0.91)$ & $0.87(0.58-1.31)$ \\
\hline
\end{tabular}

Data provided as odds ratio $(95 \% \mathrm{CI})$.

${ }^{*} P<.01$.

${ }^{\dagger} P<.05$.

${ }^{\ddagger} P<.10$

socioeconomic factors. In addition, the positive relationship we found between health care quality ratings and patient-provider language concordance did not differ markedly between major US Latino ethnic subgroups. Our findings suggest that language concordance between the patient and the health care provider plays an important role in health care communication and quality ratings by foreign-born Latinos in the United States.

To achieve the Institute of Medicine's and the Agency for Health Care Research and Quality's goals to reduce ethnic/racial health care disparities, it is essential to first specify the proper source of those disparities. ${ }^{3,4}$ Although several studies have implicated patients' English proficiency as the source of language barrier problems, our findings indicate that health care quality is rated lower when the patient and provider are speaking different languages. Unlike other previous studies, we evaluated both English proficiency and patient-provider language concordance to understand the relative contribution of each. The market demands of Latino health care consumers will continue to increase during the upcoming decades. ${ }^{2}$ It is vital for the US health care system to be adequately prepared to meet 
Table 3. Ordered Logistic Regression Model Results from the Pew Hispanic Center/Robert Wood Johnson Foundation Latino Health Survey of Models of Patient and Provider Language Use and Health Care Quality Ratings among Foreign-Born Latinos Who Received Medical Care during the Past 12 Months in the United States (n = 2663)

\begin{tabular}{|c|c|c|c|}
\hline & \multicolumn{3}{|c|}{ Quality of Care } \\
\hline & Model 1 & Model 2 & Model 3 \\
\hline English proficiency & $1.04^{\ddagger}(0.99-1.10)$ & - & $1.03(0.98-1.09)$ \\
\hline Language concordance & - & $1.44^{*}(1.12-1.84)$ & $1.42^{*}(1.11-1.82)$ \\
\hline \multicolumn{4}{|l|}{ Income (US\$) } \\
\hline $0-14,999$ & 1.00 & 1.00 & 1.00 \\
\hline $15,000-24,999$ & $0.99(0.78-1.25)$ & $0.99(0.78-1.26)$ & $0.98(0.77-1.24)$ \\
\hline $25,000-34,999$ & $0.94(0.73-1.22)$ & $0.97(0.75-1.25)$ & $0.96(0.74-1.24)$ \\
\hline $35,000-59,999$ & $0.94(0.72-1.22)$ & $0.97(0.74-1.26)$ & $0.94(0.72-1.22)$ \\
\hline$\geq 60,000$ & $1.54^{\dagger}(1.06-2.25)$ & $1.72 *(1.18-2.50)$ & $1.62^{\dagger}(1.10-2.39)$ \\
\hline \multicolumn{4}{|l|}{ Education } \\
\hline $0-8$ years & 1.00 & 1.00 & 1.00 \\
\hline $9-11$ years & $1.36^{*}(1.07-1.74)$ & $1.42 *(1.11-1.81)$ & $1.38^{*}(1.08-1.77)$ \\
\hline High school graduate & $1.18(0.93-1.49)$ & $1.26^{\ddagger}(0.99-1.60)$ & $1.21(0.95-1.55)$ \\
\hline Some college & $1.44^{\dagger}(1.06-1.94)$ & $1.56^{*}(1.17-2.07)$ & $1.46^{\dagger}(1.07-1.99)$ \\
\hline College degree or higher & $1.63 *(1.12-2.36)$ & $1.84^{*}(1.29-2.63)$ & $1.69^{*}(1.16-2.48)$ \\
\hline Health insurance coverage & $1.25^{\dagger}(1.04-1.50)$ & $1.25^{\dagger}(1.04-1.51)$ & $1.24^{\dagger}(1.03-1.49)$ \\
\hline
\end{tabular}

Data provided as odds ratio (95\% CI).

${ }^{*} P<.01$.

${ }^{\dagger} P<.05$.

${ }^{\ddagger} P<.10$.

the needs of Latino consumers to ensure a healthy and competitive population. ${ }^{16,17}$

Our patient-provider language concordance and higher health care quality rating findings are consistent with smaller, regional clinical samples of ethnic Latino subgroups and are the first to extend those previous findings to the national level. ${ }^{11,12}$ The Institute of Medicine's and the Agency for Health Care Research and Quality's recommendations for reducing health disparities focus on improving health care and not modifying the cultural characteristics of patients. Although English language proficiency may play a modest role in health care, our findings highlight the importance of language-concordant dialogue between patients and providers for improved health care quality ratings. Therefore, our findings support the Institute of Medicine's recommendations on modifying the health care delivery system and not the characteristics of patients to improve health care quality for Latinos. ${ }^{16,17}$ Furthermore, because markets are changing with the rapid rise in Latino populations throughout the United States, providers should consider accommodating patients' cultural and lan- guage needs and literally speak the same language to be competitive in those changing markets.

At least 2 modes of improving patient-provider language concordance are available: (1) improving the quantity and quality of language interpreters and (2) increasing the number of providers who are fluent in Spanish. In a recent systematic review, Karliner and colleagues ${ }^{8}$ reported that the use of well-trained, professional interpreters was associated with positive benefits in patient-provider communication, use and clinical outcomes, and patient care satisfaction. However, the authors noted that training of professional interpreters varied widely between institutions and ranged from several hours to more than a year. The second approach for reducing health disparities by removing cultural and language barriers to care is to increase the number of bilingual and bicultural health care providers in an effort to match the characteristics of the US patient population. ${ }^{18}$ Training physicians, regardless of ethnicity, to provide Spanish language-concordant care reported improved Spanish comprehension, but improvements in oral Spanish proficiency were not sustained. ${ }^{19}$ Several studies 
have demonstrated that ethnic and racial minority patients seek care providers with similar ethnic/ racial backgrounds. ${ }^{20}$ In addition, ethnic/racial minority patients rate their health care quality higher when they see culturally matched care providers. ${ }^{21}$ However, even though Latinos represent more than $15 \%$ of the US population, Latinos represent only approximately $5 \%$ of the physician workforce in the United States. ${ }^{22}$ The US Latino population is forecasted to increase to more than $33 \%$ by year $2050 .^{2}$ US health care must shift to accommodate the coming demographic changes to meet the needs of patients, to be competitive, and to ensure the health of the nation. ${ }^{16,17}$

We have provided evidence that patient-provider language concordance is associated with perceptions of better and less biased health care quality among Latinos in the United States. Nevertheless, our findings should be interpreted in the context of several caveats. First, we relied on patient selfreports, which lacked the level of detail of the actual clinical experience and other objective indicators of care quality (eg, medical outcomes). Indepth mixed design studies (ie, qualitative and quantitative) may be needed to accurately depict the qualities of communication during clinical encounters related to patient-provider language concordance and to relate those qualities to health outcomes and health care use. Secondly, the Pew Hispanic Center/Robert Wood Johnson Foundation Latino Health Survey was a telephone survey based on comprehensive lists supplied by an established commercial vendor, which could bias our estimates. Design weights were modified after the survey collection was completed to compensate for unit nonresponse and adjust the distribution of the obtained sample by sex, age, nativity, and education of Latinos in the March 2007 supplement of the Current Population Survey. Thirdly, the data were cross-sectional and, consequently, causality cannot be inferred from our study results. Fourthly, we examined several covariates associated with health care quality and satisfaction in our statistical models; however, other variables not examined may have additional explanatory value beyond those included herein. Furthermore, patients in high-density Latino areas may be able to self-select the ethnicity and language of their providers, a factor that was not accounted for in our study. It may be that patients without choice would be most likely to encounter perceived bias and rate their care less favorably. Finally, because this is the first national study to examine both patient language proficiency and patient-provider language concordance, other work would be needed to support our study inference of the central role of patient-provider language concordance.

\section{Conclusions}

When patients and providers speak the same language, foreign-born Latinos report that communication is improved and health care quality is perceived as better. The Institute of Medicine and Agency for Health Care Research and Quality have identified language barriers as key factors related to the goal of eliminating ethnic/racial health care disparities. Our findings indicate that, although patient language proficiency is important to health care quality, what may matter more is when patients and providers speak the same language.

\section{References}

1. US Census Bureau. American Community Survey, 2008. Available at: http://factfinder.census.gov/ servlet/DatasetMainPageServlet?_program=ACS\&_ submenuId = \&_lang $=$ en\&_ds_name $=$ ACS_2008_3YR G00_\&ts=. Accessed 27 September 2010.

2. Census. Current Population Series. Available at: http://www.bls.census.gov/cps_ftp.html\#cpssupps. Accessed 27 September 2010.

3. Cooper LA, Roter DL. Patient-provider communication: the effect of race and ethnicity on process and outcomes of healthcare. In: Smedley BD, Stith AY, Nelson AR, editors. Unequal treatment: confronting racial and ethnic disparities in health care. Washington, D.C.: National Academy Press; 2002. p. 552-93.

4. Agency for Health Research and Quality. National healthcare disparities report. Rockville, MD: Agency for Health Research and Quality; 2008.

5. Flores G. The impact of medical interpreter services on the quality of health care: a systematic review. Med Care Res Rev 2005;62:255-99.

6. Pippins JR, Alegria M, Haas JS. Association between language proficiency and the quality of primary care among a national sample of insured Latinos. Med Care 2007;45:1020-5.

7. Wisnivesky JP, Kattan M, Evans D, et al. Assessing the relationship between language proficiency and asthma morbidity among inner-city asthmatics. Med Care 2009;47:243-9.

8. Karliner LS, Jacobs EA, Chen AH, Mutha S. Do professional interpreters improve clinical care for patients with limited English proficiency? A systematic review of the literature. Health Serv Res 2007; 42:727-54.

9. Escarce J, Kapur K. Access to and quality of health 
care. In: Tienda M, Mitchell F, eds. Hispanics and the future of America. Washington, D.C.: National Academies Press; 2006:410-46.

10. Hodgkin D, Volpe-Vartanian J, Alegria M. Discontinuation of antidepressant medication among Latinos in the USA. J Behav Health Serv Res 2007;34: 329-42.

11. Perez-Stable EJ, Napoles-Springer A, Miramontes JM. The effects of ethnicity and language on medical outcomes of patients with hypertension or diabetes. Med Care 1997;35:1212-9.

12. Manson A. Language concordance as a determinant of patient compliance and emergency room use in patients with asthma. Med Care 1988;26:1119-28.

13. Livingston G, Minushkin S, Cohn D. Hispanics and health care in the United States: access, information and knowledge. Washington, D.C.: Pew Hispanic Center/Robert Wood Johnson Foundation; 2008. Available at: http://pewhispanic.org/files/reports/91. pdf. Accessed 27 September 2010.

14. The American Association for Public Opinion Research. Standard definitions: final dispositions of case codes and outcome rates for surveys. Revised 2009. Available at: http://www.aapor.org/AM/Template.cfm? Section $=$ Standard_Definitions $\&$ Template $=/ C M /$ ContentDisplay.cfm\&ContentID $=1819$. Accessed 16 September 2010.

15. Williams R. Generalized ordered logit/partial proportional odds models for ordinal dependent variables. Stata J 2006;6:58-82.
16. Wu S, Ridgely MS, Escarce JJ, Morales LS. Language access services for Latinos with limited English proficiency: lessons learned from Hablamos Juntos. J Gen Intern Med 2007;22(Suppl 2):350-5.

17. Perez-Stable EJ, Salazar R. Issues in achieving compliance with antihypertensive treatment in the Latino population. Clin Cornerstone 2004;6:49-61; discussion 62-4.

18. Barona A, Santos de Barona M. Chapter 4: Recommendations for the psychological treatment of Latino/Hispanic populations. In: Psychological treatment of ethnic minority populations. Council of National Psychological Associations for the Advancement of Ethnic Minority Interests, ed. 2003. Available at: http://www. psychologymatters.org/pi/oema/resources/brochures/ treatment-minority.pdf\#page $=202003$. Accessed 16 September 2010.

19. Reuland DS, Frasier PY, Slatt LM, Aleman MA. A longitudinal medical Spanish program at one US medical school. J Gen Intern Med 2008;23:1033-7.

20. Chen FM, Fryer GE Jr, Phillips RL Jr, Wilson E, Pathman DE. Patients' beliefs about racism, preferences for physician race, and satisfaction with care. Ann Fam Med 2005;3:138-43.

21. Saha S, Taggart SH, Komaromy M, Bindman AB. Do patients choose physicians of their own race? Health Aff (Millwood) 2000;19:76-83.

22. American Medical Association. Physician characteristics and distribution in the US, 2002-2003. Chicago, IL: American Medical Association; 2001. 